\title{
Las condiciones históricas de posibilidad del General Point of View: una solución evolutiva al problema metaético humeano del cognitivismo moral ${ }^{*}$
}

Recibido: febrero 17 de 2016 | Aceptado: diciembre12 de 2016

DOI: 10.17230/co-herencia.14.27.11

\section{Santiago Álvarez García** \\ sanalvgar@alum.us.es}

Resumen El presente artículo ofrece una solución al problema metaético que florece en la ética humeana a propósito de la conciliación entre el cognitivismo derivado de la exigencia del General Point of View y el internalismo moral que se deriva de su argumento de la motivación. Asumiendo una descripción evolutiva en la construcción de la perspectiva evaluativa representada por el General Point of View, al tiempo que un proyectivismo epistemológico para los juicios causales que conectan las motivaciones, acciones y utilidad de los distintos caracteres que surgen en el origen de la justicia, se puede conciliar -sin riesgo para la consistencia del planteamiento humeano- la existencia de individuos capaces de generar juicios morales cognitivos que derivan en una motivación moral internalista, identificada con el sentido del deber, e individuos con motivaciones claramente externalistas basadas en el uso instrumental de la razón.

\section{Palabras claves:}

Cognitivismo moral, General Point of View, proyectivismo, cuasi-realismo, internalismo moral.

Historical conditions of possibility of the General Point of View: an upgradable solution to the metaethical Humean problem of moral cognitivism

\footnotetext{
Abstract This paper offers a solution to the metaethical problem that flourishes in Hume's ethics concerning the conciliation between the cognitivism derived from the demands of the General Point of View and the moral internalism that results from its reasoning of motivation. Through the assumption of an evolutionary description in the construction of an evaluative perspective represented by the General Point of View, and at the same time an epistemological projectivism for the causal judgments that connect
}

Este artículo es parte de mi tesis doctoral, titulada La teoría de la justicia de David Hume, dirigida por Antonio Hermosa Andújar y defendida en 2016 en la Universidad de Sevilla en el Departamento de Estética e Historia de la Filosofía. Este texto supone la síntesis de una de las partes fundamentales de la tesis, de cara a la comprensión de los límites morales del agente político.

** Doctor en filosofía por la Universidad de Sevilla, España. ORCID: 0000-0002-1069-8807 
motivations, actions and usefulness of the different characters that emerge from the origins of justice, it can be reconciled -with no risk against the consistency of Hume's approach- that there is existence of individuals who are capable of creating cognitive moral judgments resulting in an internalist moral motivation, which is identified with the sense of duty, and individuals with clearly externalist motivations based on the instrumental use of reason.

\section{Keywords:}

Moral cognitivism, General Point of View, projectivism, quasi-realism, moral internalism.

\section{El problema metaético en la moral humeana}

No constituye una exageración afirmar que la mayoría de los intérpretes que se han enfrentado al abrupto territorio de argumentos de Hume acerca de la evaluación y la motivación moral se forman de la enmarañada propuesta del escocés un juicio común: el de la inconsistencia. En el caso que nos ocupa, sin embargo, el calificativo con el que se vuelve a describir la propuesta de Hume: el "problema metaético", es el resultado de un conflicto anacrónico al que el autor ha sido invitado y dentro del cual sus argumentos, forzados a ser entretejidos con nuevos mimbres, proyectan otras sombras sobre la ya dañada coherencia de sus escritos. El "problema metaético" contemporáneo, tal y como lo define Sayre-McCord (1997), emerge de la adopción de la teoría de la motivación humeana por parte del naturalismo moral. De la combinación de ambas perspectivas teóricas surge una conclusión conflictiva para la propia propuesta humeana: la incompatibilidad manifiesta entre el cognitivismo y el internalismo moral. Ambos han sido asumidos por Hume en su propuesta: de un lado, el internalismo moral como clave de bóveda del ataque al racionalismo; del otro, una suerte de subjetivismo cognitivista en la condición del General Point of View, inexcusable para la gestación de la evaluación y el juicio moral.

La convivencia de argumentos que favorecen con la misma solidez a una u otra postura (Sturgeon, 2008), tanto en el Treatise como, en menor medida, en la segunda Enquiry, ha preñado la bibliografía secundaria con posicionamientos enfrentados y difícilmente conjugables. ${ }^{1}$ Para nosotros, sin embargo, esta discordancia es el resul-

Desde los años sesenta han proliferado versiones cognitivistas y no cognitivistas que han defendido al mismo tiempo lecturas internalistas o externalistas de la motivación: entre las primeras lecturas no 
tado de un acercamiento incompleto al problema. La convivencia de lecturas irreconciliables a priori solo es nociva para la propuesta del escocés si entendemos de manera monolítica e inflexible al individuo humeano y obviamos su propio progreso antropológico y social; es decir, si no atendemos correctamente a la transformación que los procesos sociales producen en las distintas generaciones e individuos que presumiblemente los protagonizan, así como en los contextos artificiales que transitan. En este sentido, nuestro ejercicio interpretativo tratará de comprender las consecuencias de dichos procesos en los esquemas evaluativos de los individuos y su papel en la gestación histórica y colectiva del General Point of View. Comenzaremos vinculando el proceso por el que se establece la convención que da origen a la justicia con las condiciones históricas y antropológicas que posibilitan la aparición de la perspectiva evaluativa. Posteriormente mostraremos cómo la institución progresiva de la justicia y la estabilización de los caracteres y las identidades sociales permitirán la aparición, por primera vez, de la evaluación moral. Esta es, pues, un rasgo disponible solo para un determinado agente histórico situado en un momento cronológico de estabilidad social. Entendida así la evaluación moral, señalaremos cómo se irá configurando, en virtud de una proyección progresiva y colectiva, una suerte de tejido cuasi-real compuesto de juicios casuísticos a través de los cuales la información moral quedará fijada de manera casi definitiva en el artificioso imaginario colectivo. En este proceso se habilita, de un lado, el contenido susceptible de ser atribuido al espectador imparcial y que se identifica con el máximo probabilístico de juicios que relacionan motivos y consecuencias, útiles o no, asumido por la comunidad en cuestión; del otro lado, se habilita la posibilidad de acceder a ideas o creencias representativas sin impresión previa, fundamentales para la autoevaluación y el ajuste, con los que se originan el sentido del deber y la motivación interna.

cognitivistas y defensoras del internalismo se encuentran las de Flew (1963), Foot (1963), Hudson (1964), Harrison (1976), Stroud (1977) y Mackie (1980). Del lado cognitivista y externalista encontramos a Darwall (1993). Por su parte, Brown (1988) defiende un externalismo no vinculado a la lectura cognitivista. Recientemente encontramos lecturas no cognitivistas, como la de Sturgeon (2008), y cognitivistas, como las de Cohon $(1997,2001)$ o, más recientemente, la de Radcliffe (2006), que aúna en una lectura original cognitivismo e internalismo. 
Con dicha descripción estaremos en condiciones de completar los esfuerzos de Radcliffe (2006) por conjugar el internalismo moral y el cognitivismo, ofreciendo una descripción del origen histórico y epistemológico del polo cognitivo que sirve de patrón para las autoevaluaciones morales, al tiempo que ampliamos su propia concesión al presumible cognitivismo humeano. Sin embargo, previamente al análisis histórico, bosquejaremos el ramillete de problemas internos que el General Point of View supone en la doctrina del propio Hume, para mostrar al final del artículo cómo nuestra propuesta interpretativa los resuelve.

\section{Los problemas del General Point of View como con- dición para la evaluación moral}

La teoría del General Point of View es la respuesta a dos objeciones fundamentales que el propio Hume entendía podrían hacérsele a su propuesta sentimentalista. De un lado, la objeción de la "variabilidad de la sympathy" (Hume, [1739] 1978, p. 581), que afirma la imposibilidad de que un mecanismo tan parcial como la sympathy se convierta en el fundamento de la aprobación moral, toda vez que esta requiere, al menos, un cierto halo de objetividad. Del otro, la objeción denominada "virtue in rags" (Hume, 1978, p. 585), según la cual, si la teoría de la sympathy fuera correcta, tan solo aprobaríamos aquellos caracteres que arrojaran información actual acerca de la virtud de las personas. Así pues, la necesidad de un punto de vista común revelaba, aún muy soterradamente, la idea de que la moral como contenido sentimental y evaluativo al alcance de los individuos cobra relevancia práctica allí donde la sympathy comienza a mostrar sus naturales carencias. Estas pueden permanecer solapadas y ocultas mientras la comunidad no exceda demográficamente el número que hace saltar por los aires la "paz" acrítica de la que disfrutan sus miembros, merced al amor y al orgullo comunitarios.

Para sortear sendas objeciones, Hume se vio obligado, en primer lugar, a establecer una diferenciación entre los placeres para hacer factible la peculiaridad del sentimiento moral frente a los demás, y evitar así caer bajo la objeción de una posible moralidad en los 
objetos inanimados (1978, p. 471). La diferenciación cualitativa entre los placeres se ve avalada por la experiencia, que permite a los sujetos distinguir entre los placeres de la mesa, como el vino, y aquellos denominados estéticos, relacionados con el arte y la música (p. 472). La posibilidad de la evaluación moral depende, pues, de la capacidad que el placer y sus gradaciones ofrecen para el refinamiento. Su manifestación, como más tarde confirmaría Hume en la segunda Enquiry ([1751] 2014, p. 116) y en el ensayo Of the Standard of Taste, vincula ya la aparición del juicio moral con la consolidación estable de una sociedad capaz de retroalimentarse, al punto de generar un estándar para valorar y calibrar la certeza o no de las propias reacciones sentimentales.

Así, solo desde una posición neutral, ajena a los intereses más egoístas y a los ejercicios parcializadores y limitadores de la sympathy, puede el individuo aspirar a sentir una emoción que cristalice en una aprobación susceptible de ser asumida por el resto de la sociedad y que, por ende, pueda denominarse moral. Esto es así porque adoptar el General Point of View implica atender a la utilidad del carácter de la persona evaluada para su círculo más próximo y, por extensión, para el resto de la humanidad (Hume, 2014, p. 175); así como juzgar sus características de acuerdo con los efectos usuales que caracteres de ese tipo pueden producir y que están cifrados en las "general rules" generadas por la propia comunidad (Hume, 1978, p. 585).

Estas condiciones de posibilidad, sin embargo, entran en conflicto con las limitaciones epistemológicas y pasionales del agente que el propio Hume había formulado en los dos primeros libros del Treatise; sobre todo, en lo relativo a la casuística de la motivación que conduce al sujeto a adoptar el General Point of View. Dos eran, fundamentalmente, los argumentos que Hume establecía para dar respuesta motivacional a la adopción del General Point of View. El primero de ellos era el denominado "Stability Argument": Hume afirmaba que adoptamos el General Point of View porque nos proporciona las creencias más estables y consistentes sobre los caracteres. Frente a la posibilidad de contradicciones y errores en la evaluación y el juicio acerca de los caracteres de los individuos, debido a la par- 
cialidad y a la dependencia posicional de la sympathy (Hume, 1978, p. 581), surge en nosotros la necesidad de ubicar un espacio común desde el cual dotar las evaluaciones de una "objetividad" y "universalidad" que hagan posible la comunicación entre los observadores, sobre unos criterios y estándares estables; es decir, adoptamos el General Point of View por razones fundamentalmente epistemológicas y comunicativas. Esta explicación motivacional confirma, de manera indirecta, la convicción que subyace en este artículo de que tras la convención originada por la justicia, esta perspectiva evaluativa objetiva se hace necesaria y se encuentra disponible, ya que en la pequeña comunidad -previa a la aparición del conflicto de las posesiones- no puede darse confusión evaluativa alguna, dada la interrelación acrítica de pasiones como el orgullo y el amor entre los componentes de la comunidad (1978, pp. 348, 353). El otro argumento de Hume era el denominado "Agreement Argument". Según él, adoptamos el General Point of View porque nos ayuda a alcanzar acuerdos sobre el juicio de los caracteres y no tanto porque necesitemos una referencia epistemológica firme; nuestra razón para ser morales no sería entonces epistémica, sino eminentemente práctica.

La solidez de la convicción señalada arriba se hace más evidente, si cabe, cuando analizamos los problemas hermenéuticos suscitados en los intérpretes debido a las razones motivacionales aducidas por Hume para adoptar el General Point of View. Las propuestas motivacionales en torno al espectador ideal contienen en sí el problema de determinar qué clase de juicios generan la controversia que hace florecer la necesidad del punto de vista común. No podemos en este caso considerar los juicios morales dentro de la panoplia de candidatos, ya que caeríamos en la circularidad, toda vez que el propio General Point of View es necesario para la existencia de tales juicios en conflicto. Si asumimos, sin embargo, simples juicios de amor y de odio, la propia necesidad de paliar una contradicción se revela contradictoria e ilegítima, ya que en ningún caso podría darse "confusión" alguna entre juicios sin carga representativa y puramente sentimentales. ¿Por qué corregir nuestra posición? ¿Por qué enmendar algo que no es sino un puro sentimiento? Una respuesta plausible es la que, una vez establecidas y consolidadas las normas de justi- 
cia y el tratamiento imparcial de los individuos, entiende en clave histórica la necesidad de instituir estándares evaluativos capaces de ofrecer los mismos beneficios en las relaciones y en la comunicación interpersonal a los individuos de una sociedad incipiente. Cuando el amor trasciende el marco reducido de la comunidad primitiva, exige una reformulación análoga a la que progresivamente y de la mano de la convención ha iluminado los desajustes del malogrado self-interest. Mantener estable una sociedad que empieza a volverse compleja implica, pues, constituir un estándar de lo que se debe o no amar; es decir, cifrar en el ideario colectivo, y con la ayuda del paso del tiempo y la costumbre, la probabilidad más alta en la tendencia de los sentimientos a la aprobación o desaprobación, con base en los juicios causales que determinan las diferentes utilidades sociales de las distintas motivaciones.

Otro de los problemas que sobreentienden la necesidad de un refinamiento y, por ende, señalan de manera indirecta el carácter histórico de la posición evaluativa común, es el presentado con acierto por Miller (1984) a propósito de la influencia de la imaginación a la hora de la adopción del General Point of View. Este exige en cierta medida un punto de abstracción, y es la imaginación la que nos permite colocarnos allí. En este sentido, un problema saltaría al frente en el caso de que el agente evaluador siguiera sus principios más "irregulares": sus valoraciones morales, articuladas por las "general rules" parciales con las que actúa la imaginación, quedarían vinculadas al resultado azaroso de la puesta en práctica de los prejuicios. Es decir, evitar este problema implica entender que el uso de las conexiones de la imaginación debe ser, cuanto menos, sofisticado (1984, p. 56). El General Point of View, para ser realmente un criterio moral, necesita un ejercicio de la imaginación instituido sobre sólidos y estables principios. Por eso, en realidad solo el "sabio", capaz de sobreponerse a las conexiones causales más débiles o aparentemente azarosas de las que no escapa el vulgo, estaría en posición de ocupar el lugar privilegiado para formular el juicio y la evaluación moral.

La puntillosa observación de Miller nos obliga a asumir dos escenarios posibles para salvar la propia coherencia interna humeana: 
o bien solo un sector de la población está en posición de adoptar ese punto de vista, o bien este es accesible una vez que los diferentes juicios probabilísticos en torno a la relación entre motivaciones y utilidades o beneficios sociales han cristalizado, alcanzando un consenso tácito en los individuos, a partir del cual se dotan de contenido las hipotéticas reacciones evaluativas de ese pretendido espectador ideal -identificable aquí con el sabio traído a colación por Miller. La que sostenemos aquí es la segunda de estas posiciones, que a su vez resuelve el problema que surge del carácter marcadamente hipotético del juicio de evaluación moral bajo las "general rules". Hume no dejó claro el problema de cómo debe el espectador considerar la acción, es decir: ¿solo tiene que contemplar la acción y su efecto directo y experimentable o por el contrario debe, desde su posición desactualizada, tener en cuenta también las consecuencias a largo plazo de la misma sobre todos aquellos susceptibles de ser afectados por ella? Frente a este problema, la maraña tejida en el tiempo por la sociedad ofrece a la posición desactualizada del observador el ramillete de consecuencias más probables a largo plazo y, en este sentido, habilita la consideración largoplazista, que lo acerca al criterio de utilidad extensible a la humanidad. Por otro lado, el hecho evidente de que la teoría del "espectador imparcial" toma los juicios morales como juicios sobre reacciones hipotéticas de gente imparcial, con datos suficientes sobre los acontecimientos, no supone ya un conflicto, toda vez que la totalidad de la información se reduce al propio consenso informacional en torno a las consecuencias y los motivos que históricamente se han ido asumiendo en la sociedad, hasta convertirse en el stock moral de la comunidad. Las evaluaciones morales serían entendidas ahora como inductivamente fundamentadas. Es decir, como creencias empíricas sobre lo que se sentiría si alguien ocupase ese punto de vista genérico, asumiendo que, al menos, una vez la información moral se constituye en el contexto artificial de los individuos, vicio y virtud aparecerán como cuestiones de hecho susceptibles de ser descubiertas a través del razonamiento empírico. 


\section{La creación del espacio moral: la aparición del Gene- ral Point of View como posibilidad evaluativa}

Los distintos argumentos y problemas que se han dibujado a propósito de la correcta comprensión del General Point of View humeano han señalado con precisión un momento sociopolítico específico como el lugar clave para su constitución histórica: la convención para la formación de las reglas que configuran la justicia. Esgrimiremos algunas de las razones - a nuestro modo de ver, concluyentesque muestran cómo las consecuencias de la convención habilitan históricamente al agente humeano para construir primero y acceder después a una posición evaluativa transposicional.

¿Cómo una convención basada en el interés contingente de los individuos transforma nuestra psicología moral y la vuelve "compartible", al punto de poder alcanzar acuerdos sobre el valor de ciertos caracteres? (Taylor, 1998). A la hora de responder esta pregunta, nuestra lectura se posicionará contra los que asumen la existencia de un sentido moral no cultivado correspondiente a un estadio en que el agente reconocería la parcialidad como un valor natural que, sin embargo, se revelaría incapaz de resolver el problema de la avidez y de ofrecer mecanismos para la aprobación de la acción justa, por lo que exigiría una suerte de sofisticación, de la que la convención y su particular desarrollo se encargarían (1998, p. 11). La estructura natural de esa primera "moralidad", que algunos asumen en las composiciones sociales previas a la convención, residiría en nuestra capacidad para valorar moralmente las parcialidades que considerásemos fundamentales para el propio bienestar comunitario (Hume, 1978, pp. 478, 488). Sin embargo, ya A. D. Woozley (1978) a finales de los setenta evidenciaba lo que a su modo de ver constituía una falacia terrible dentro del planteamiento de la aprobación o desaprobación de las virtudes naturales, al margen del contexto artificial generado por la convención: no existe un motivo, por fuera del sentido del deber artificial, capaz de corregir un vicio aparentemente natural, como el de la ausencia del cariño por los hijos; por lo tanto, la desaprobación moral de tal vicio, en este sentido, 
sería ilegítima. ${ }^{2}$ Pero ipuede el individuo antes de la convención ser capaz de extrapolar en forma de evaluación o juicio moral lo que en su comunidad considera esencial? Es decir, ¿puede el individuo antes de la convención evaluar ya desde un General Point of View? La respuesta es no. En la parcialidad natural del individuo reside primitivamente todo lo que más tarde se convertirá en nuestro contenido moral: todas sus tendencias emocionales, sus creencias y las conexiones imaginativas que le conducirán a vincular ciertos motivos, deducidos de ciertas acciones, a resultados más o menos útiles. Sin embargo, a diferencia de lo que piensa Taylor, solo tras la convención estas tendencias, creencias y convenciones se extenderán y convertirán en contenido y creencia colectiva, una vez que el ejercicio de la imparcialidad produzca su efecto pedagógico sobre los sujetos y habilite la aparición del General Point of View como una posibilidad evaluativa. Así, el error de Taylor, como el de otros tantos, es considerar los estándares de la parcialidad, producto de nuestro sentimiento comunitario, como una uncultivated moral, es decir, como una capacidad moral en el individuo y no como el germen del que, a través de la convención, surgirá por primera vez la evaluación moral entendida como tal.

La aparición de la convención no es la manifestación de una virtud -en este caso, artificial- dentro de un escenario moral poco cultivado, sino muy al contrario, es el paso previo para la génesis de dicho contexto. La constitución de la convención genera elementos fundamentales para entender la aparición de la moral como posibilidad. De un lado, la idea misma de interés público, que implica la necesidad de una lectura lo más común posible de los demás, y también la experiencia, al menos, de la corrección de nuestro amor parcial (un amor, por cierto, que antes de la convención no entraba en conflicto con los intereses propios de la comunidad, dadas las vinculaciones comunitarias y "parroquiales" en las que el orgullo asume el

\footnotetext{
A propósito del ejemplo del padre que carecía de amor por sus hijos y que Hume utilizaba para mostrar la falta de una motivación que, bajo la luz de las virtudes naturales, se consideraba congénita a la naturaleza humana, Woozley (1978) señalaba la necesidad de asumir, para la evaluación moral del padre, que este tuviera alguna opción de cuidar al niño mejor; es decir, que dispusiera de los medios y los motivos necesarios para actuar de este modo. Sin embargo, la paradoja surgía: ¿cómo recomendar a un padre que no ama a su hijo que lo cuide, cuando solo podría hacerlo si amara a su hijo?
} 
liderazgo de la gestación de las distintas identidades y proyectos de vida). Del otro, la aparición de una primera normatividad implícita que los individuos empezaban a gestar, a través de las reglas de propiedad con que superaban la inestabilidad de las posesiones, reglas que podrían volverse inmanentes y generar lo que Hume acabará denominando "sense of duty" (Besser-Jones, 2006). Por último, la constitución de la convención genera la asimilación progresiva de las normas de justicia, asimilación que Hume entiende análoga a la del lenguaje y que implica la corrección-progresión sentimental del hombre (King, 1981, p. 38) y, con ella la construcción casi necesaria de un General Point of View.

Además, en su desarrollo histórico la convención configura un elemento fundamental e imprescindible para la aparición de un juicio moral: la consolidación de la personalidad o el carácter. La ética de la virtud en Hume entiende que el objetivo fundamental de la evaluación moral es la aprobación o desaprobación del carácter personal, para lo cual la teoría exige caracteres estables que constituyan con meridiana solidez una identidad de cara a los demás. La pregunta que cabe hacerse es, entonces: ¿es posible la estabilización del carácter -para que pueda ser evaluable moralmente- en el contexto previo a la convención? No se trata en ningún caso de una pregunta baladí, si tenemos en cuenta la necesidad de una sociedad con esquemas estables de medición y comparación de lo que poseemos y poseen los demás, a la hora de establecer cuál es nuestro estatus. En este sentido, es difícil visualizar el agente con una identidad firme en el contexto previo a la convención. De hecho, fue precisamente esa inestabilidad una de las causas de la búsqueda de solución al conflicto que surgía de la facilidad con que las posesiones pasaban de unas manos a otras sin el consentimiento de sus poseedores, debido a que estos perdían cualquier posibilidad de presentar su posición social a los demás, para el posterior desarrollo estable de su orgullo y su identidad vinculada. Así pues, el principal resultado de la convención, además de la estabilidad de las posesiones, sería la configuración de las diferentes stations of life, fundadas en el statu quo originario y en el incipiente esquema de honores que florecía. 
Tras la convención, el agente sabe con certeza con qué posesiones cuenta de cara al resto de individuos que componen la sociedad y con cuáles cuentan los demás. Se sabe con una identidad social y al mismo tiempo entiende así a los otros. La vinculación entre identidad, cualidad moral y posesiones es una tónica en el Treatise y en la segunda Enquiry. El principal efecto de este acontecimiento artificial es, pues, el de consolidar la posición social y los mecanismos adecuados para escalar dentro de la sociedad. Si tenemos en cuenta la relación entre estatus, posesión e identidad, podemos afirmar con rotundidad que la convención, en el fondo, no es sino la manera de estabilizar o fijar la identidad social y configurar, a partir de ahí, el carácter que después será susceptible de evaluación moral. Una evaluación moral que será facilitada por la posibilidad de prever los comportamientos, que permite articular los patrones que relacionan acciones y motivos aceptados en cada station of life y que surge una vez los individuos dan muestras de confianza recíproca en el cumplimiento de las leyes que regulan la propiedad. Hume lo señala en el Treatise cuando afirma: "this experience assures us still more, that the sense of interest has become common to all our fellows, and give us a confidence of the future regularity of their conduct: And 'tis only on the expectation [...] founded" (Hume, 1978, p. 490).

Es la primera vez que el individuo humeano está predispuesto a asumir la regularidad y a establecer para sí un modo de comportamiento fijo, dadas las normas que regulan el escenario social en el que actúa. Es ahí cuando la necesidad de nuevos marcos comunes aflora, y donde, por defecto, el argumento de la corrección epistemológica de las evaluaciones cobra sentido. El efecto de la convención, en este sentido, es doble: de un lado se consolidan las distintas identidades individuales $y$, con ellas, las diferentes relaciones entre motivos y acciones en las diversas stations of life. Del otro, se gesta un nuevo espectador, que ya no está terriblemente sujeto a lo azaroso del contexto y a su sympathy parcial, sino que se sabe preparado para rastrear detrás de cada acción individual los motivos y las intenciones del agente, dado el marco de estabilidad desde el que presupone la acción. 


\section{La creación progresiva de la información moral por la comunidad}

Establecido el origen histórico y social de las condiciones de posibilidad del General Point of View, queda por justificar la lectura que hemos asumido en favor de la creación de un entorno estructural de creencias morales. Con este propósito, trataremos de describir desde una óptica evolutiva cómo los individuos, situados en distintas fases del desarrollo de la convención, admiten diferentes interpretaciones - cognitivistas y no cognitivistas- de sus evaluaciones y juicios morales y causales, y cómo estas se conjugan sin que por ello brote contradicción o inconsistencia alguna.

El núcleo central del no cognitivismo es la tesis que defiende que el "estado mental" de una persona que acepta una afirmación moral básica no es una creencia ni otro tipo de estado cognitivo, sino un estado conativo o motivacional similar a un deseo (Blackburn, 1993). Dos son las principales interpretaciones de la metaética humeana que asumen el no cognitivismo y, por defecto, el antirrealismo: el proyectivismo y el perceptivismo moral. El primero surge como respuesta a uno de los problemas típicos dentro de la perspectiva no cognitivista, que es el que denuncia el carácter "aparentemente" cognitivo del discurso moral con el que nos manejamos a diario. Blackburn afirma que al moralizar cada día, hablamos de creencias y asumimos como verdaderamente real, objetiva y trascendente una suerte de "superficie realista"; es decir, tratamos el escenario moral - los juicios en torno a la utilidad o no de determinadas intenciones o motivos asociados a distintas acciones- de una manera que podríamos denominar cuasi-realista. Hablamos como si esas tendencias conativas de nuestros estados mentales fueran creencias, como si, efectivamente, el mundo estuviera compuesto por propiedades morales, y lo hacemos porque proyectamos sobre la realidad esos estados (Pitson, 1989; Olson, 2011; Kail, 2009). La base de esta lectura reside, de un lado, en establecer una analogía con lo que ocurre en el plano epistemológico cuando generamos juicios causales. Al hacerlo, de una u otra forma proyectamos las ficciones útiles con las que nuestra imaginación estructura las impresiones que se presentan 
bajo la relación de contigüidad o semejanza y se las atribuimos ilegítimamente al objeto u objetos y su relación. Según esta lectura, un juicio moral no solo es la manifestación de una emoción, sino que además es la atribución de virtud o vicio a una acción o un carácter. Varios son los pasajes tanto en el Treatise (Hume, 1978, pp. 167, 469) como en la segunda Enquiry (Hume, 2014, pp. 205-206) que justifican esta lectura. ${ }^{3}$ Sin embargo, aunque en el terreno gnoseológico la proyección de las ficciones como causas no plantea serios problemas, en el territorio moral sí que lo hace.

En primer lugar, indicaremos el problema que supone la propia proyección y cómo nuestra interpretación la resuelve en clave evolutiva; en segundo lugar, expondremos las razones cognitivistas que nos conducen a rechazarla para Hume en lo que respecta al juicio moral. Como ha indicado con acierto Stroud (1993), para entender la operación de proyectar en el mundo algo prestado de los sentimientos internos, tenemos que admitir que la operación nunca tendrá éxito en producir un pensamiento inteligible, que atribuya ciertos rasgos añadidos a los objetos externos o a las relaciones entre ellos; en lugar de esto, puede darse la ilusión de coherencia en el pensamiento, pero nada más. Efectivamente, a diferencia de los juicios de causa-efecto, en la moral no exportamos nada, simplemente experimentamos el sentimiento y generamos una "ungilded truth". Asumiendo esta lectura de Stroud, sin renunciar al proyeccionismo, solo nos cabe admitir que es ese individuo, aún proto-moral y ya inmerso en la convención, el que proyecta no juicios morales objetivos y evaluativos, sino proposiciones causales que comienzan a tintar el mundo con conexiones entre motivos y utilidades, procedentes de evaluaciones parciales y no estrictamente morales. Y son estas proposiciones las que configurarán, con el paso progresivo del tiempo y la consolidación de la costumbre, el escenario artificial del que se "aprenderán" los criterios susceptibles de ser atribuidos a un "espectador ideal".

Desde el punto de vista cognitivista, estamos obligados a recha-

\footnotetext{
Es célebre el pasaje que indicamos de la segunda Enquiry donde Hume afirma, a propósito del gusto: "el otro tiene una facultad productora; y dorando o tiñendo los objetos con los colores tomados a préstamo del sentimiento interno, hace que surja una nueva creación” (Hume, 2014, pp. 205-206).
} 
zar el proyectivismo en lo relativo a los juicios morales que surgirán una vez configurado el escenario artificial, no sin antes ofrecer algunos argumentos. Las distinciones morales en Hume están basadas en sentimientos de aprobación o desaprobación, y estos son impresiones de reflexión, por lo tanto, son completamente diferentes de otras ideas, que son adquiridas por impresiones de sensación acerca del mundo (Radcliffe, 2006). Los sentimientos no tienen un contenido que las ideas “copien”. En este sentido, compartimos el rechazo de Radcliffe (2006) a leer esta circunstancia desde la óptica de la analogía ficcional que opera en los juicios causales, ya que implicaría que, a pesar de poseer creencias morales, estas serían todas falsas. La moral no soporta la analogía con la "ficción exportable", en relación con la suposición de la causalidad, ya que Hume no ofrece un escepticismo sobre la moral similar al que el libro primero del Treatise deja adivinar respecto de los juicios causales. En el análisis de la causalidad, parte de la operación se oculta al individuo, quien la reproduce de forma inconsciente. Pero este no es el caso en lo concerniente a la evaluación y el juicio moral, donde el agente evaluador es plenamente consciente de cada uno de los mecanismos y resortes que activa en la gestación del sentimiento (2006, p. 360). Esto último termina de confirmar que solo cuando hay ya un consenso causal en lo relativo a la conexión entre motivos, acciones y utilidades, puede el espectador humeano adoptar el General Point of View y emitir juicios morales.

\section{Una posible solución evolutiva al problema metaéti- co humeano}

La posibilidad o no de que en Hume exista una teoría cognitivista del juicio moral pasa por mostrar si, efectivamente, su propuesta admite "creencias morales"; es decir, si lo que entendemos por juicio moral en Hume se corresponde con "una idea vivaz que representa algo o el estado mental no-representativo más vívido posible” (2006, p. 360). En este sentido, partiendo de lo ya visto, hay una doble posibilidad de que el juicio moral pueda interpretarse en términos estrictos como una creencia: de un lado, si tal creencia es definida en 
términos de sus orígenes causales en los sentimientos motivantes y si representa una creencia en nuestra virtud o nuestro vicio personal, a partir de una autoevaluación moral; es decir, los juicios morales como creencias representan cualidades reales útiles o inútiles (Radcliffe, 2006, p. 365). Del otro, hay que partir de la composición asumida por toda la sociedad y de su imaginario acerca de los juicios causales históricamente asumidos -conectando motivaciones, actos, resultados y esferas sociales- y que se han ido proyectando hasta conformar una cuasi-realidad (que no es falsa, porque los posteriores juicios morales sentimentales la confirman y consolidan como una verdad artificial humana), que se acaba constituyendo en la única realidad moral artificial disponible para las nuevas generaciones de individuos. Si se parte de aquí, el juicio moral puede interpretarse como una creencia que representa lo que el nuevo individuo entiende que percibe de ese contexto artificial; es decir, propiedades reales de las relaciones y de los caracteres de los individuos. El juicio moral puede interpretarse, pues, como una creencia. Y esta tiene como referente un estado del mundo que se asume como si procediese de una impresión fruto de la conjugación de un sentido, ya refinado, y de las cualidades de un mundo o una sociedad que ha progresado asentando un sistema de "realidades" artificiales. Este sistema, a su vez, se corresponde con el engranaje causal producido por los juicios causales e hipotéticos (en lo concerniente al largo plazo) en torno a la utilidad.

Resta comprobar si esta lectura en clave cognitivista y sustentada en la descripción histórica de las condiciones de posibilidad del General Point of View es compatible con un internalismo moral como el que predicábamos al principio del artículo.

¿Por qué debería un agente tener en cuenta, a la hora de actuar, la reacción hipotética de un espectador imparcial? ¿Cómo y de dónde extraería el agente ese sentimiento motivador que lo acercaría al estándar moral probabilístico que históricamente se ha ido asumiendo como el criterio evaluativo del espectador ideal? ¿Por qué el juicio hipotético que le presuponemos a un espectador neutral podría motivar en nosotros una corrección de nuestras propias tendencias 
pasionales? ${ }^{4}$ La motivación en el agente requiere, necesariamente, un estado interno identificable con una pasión. En este caso, si el sentido de la moralidad origina motivos, eso significaría que los sentimientos que constituyen nuestra percepción y distinción moral -a saber, los sentimientos de aprobación o desaprobación- son un estado conativo de la mente o de las pasiones. Se sigue, pues, que hacer un pronunciamiento moral es estar en un marco mental motivador y tener un motivo para un comportamiento virtuoso. Sin embargo, esto atentaría contra los cimientos de la lectura cognitivista que acabamos de defender. Será, pues, en la desaprobación de nuestras carencias, es decir, en la desaprobación de nuestro propio carácter y en el deseo de evitar la sensación desagradable que nos produce el mal llamado "odio sobre nosotros mismos" donde surgirá la motivación. ${ }^{5}$ Sin embargo, esta lectura estaría incompleta sin la confirmación de una estructura de creencias morales asentadas en la comunidad, para que dicho fenómeno pueda producirse. Es fundamental comprender -como hemos hecho en el artículo- el modo en que se gesta esa estructura de creencias para comprender quiénes y por qué ajustan sus pasiones o motivaciones desde un internalismo moral y quiénes simplemente abrazan el externalismo a partir de un cálculo instrumental que tiene como objetivo la refutación social sin más. En este sentido, y una vez establecido el estándar o el sistema de creencias, encontraremos dos tipos de agentes: uno que actuará cumpliendo con los rigores del internalismo moral, a partir de un sentido del deber originado en el ajuste de su motivación a partir de la sensación desagradable de la desaprobación moral (esta tiene su fuente en la absorción, por parte de sus calm passions, de toda la información moral disponible socialmente y que sirve de contrapeso, en términos de prudencia,

4 Radcliffe (1996) señala esta doble vertiente de la motivación distinguiendo entre "agent-internalism" y "appraiser-internalism". El primero indicaría que, si una persona tiene que realizar una acción, entonces tiene un motivo para hacerla, independientemente de su conciencia del deber de hacerla. El segundo indicaría que la motivación es interna al juicio moral en el sentido de que, si una persona acepta un determinado juicio moral, ella tiene alguna motivación para hacer lo que el juicio requiere en esa situación relevante, ya que se supone que acepta determinadas reglas generales o creencias.

5 Para Radcliffe (1996), el self-hatred no es un odio propiamente dicho, sino una autoevaluación que produce una sensación de dolor que motiva por sí misma, sin ninguna mediación. 
a sus motivaciones parciales y egoístas). Y otro que actúa desde un externalismo, y que puede convivir con este primer agente en tanto en cuanto su situación cronológica o social impida una asimilación de dicha información moral; es decir, este agente cumple con la pretendida obligación moral razonando instrumentalmente para obtener rédito sociall 


\section{Referencias}

Besser-Jones, L. (2006). The Role of Justice in Hume's Theory of Psychological Development. Hume Studies, 32(2), 253-276.

Blackburn, S. (1993). Essays in Quasi-Realism. Oxford: Oxford University Press.

Brown, C. (1988). Is Hume an internalist? Journal of the History of Philosophy, 26, 69-87.

Cohon, R. (1997). Is Hume a noncognitivist in the motivation argument? Philosophical Studies, 85, 251-266.

Cohon, R. (2001). Hume: Moral and Political Philosphy. Ahlershot: Datmouth Publishing.

Darwall, S. (1993). Motive and obligation in Hume's ethics. Nous, 27, 415-448.

Flew, A. G. (1963). On the Interpretation of Hume. Philosophy, 38, $178-$ 182.

Foot, P. (1963). Hume on Moral Judgement. In D. Pears (Ed.), David Hume: A Symposium (pp. 74-80). London: St. Martin's Press.

Harrison, J. (1976). Hume's Moral Epistemology. Oxford: Clarendon Press.

Hudson, W. D. (1964). Hume on Is and Ought. Philosophical Quarterly, $14,246-252$.

Hume, D. ([1739] 1978). A Treatise of Human Nature [L. A. Selby-Bigge (Ed.)]. Oxford: Clarendon Press.

Hume, D. ([1751] 2014). Investigación sobre los principios de la moral. Madrid: Alianza.

Kail, P. J. (2009). Projection and Realism in Hume's Philosophy. Oxford: Clarendon Press.

King, J. (1981). Hume's Classical Theory of Justice. Hume Studies, 7(1), $32-54$.

Mackie, J. L. (1980). Hume's Moral Theory. London: Routledge \& Kegan Paul.

Miller, D. (1984). Philosophy and Ideology in Hume's Political Thought. Oxford: University Press.

Olson, J. (2011). Projectivism and Error in Hume's Ethics Hume Studies. Hume Studies, 37(1), 19-42.

Pitson, A. E. (1989). Projectivism, Realism, and Hume's Moral Sense Theory. Hume Studies, 15(1), 61-92. 
Radcliffe, E. (1996). How Does the Human Sense of Duty Motivate? Journal of History of Philosophy, 34, 383-407.

Radcliffe, E. (2006). Moral internalism and moral cognitivism in Hume's metaethics. Synthese, 152, 353-370.

Sayre-McCord, G. (1997). The metaethical problem. Ethics, 108, 55-83.

Stroud, B. (1977). Hume. London: Routledge \& Kegan Paul.

Stroud, B. (1993). "Gilding or Staining" the World with "Sentiments" and "Phantasms". Hume Studies, 19(2), 253-272.

Sturgeon, N. (2008). Hume's Metaethics: Is Hume a Moral Noncognitivist? En E. Radcliffe, The Blackwell Companion to Hume (pp. 513528). Oxford: Blackwell.

Taylor, J. (1998). Justice and the Foundations of Social Morality in Hume's Treatise. Hume Studies, 24(1), 5-30.

Woozley, A. D. (1978). Hume on Justice. Philosophical Studies, 33, 81-99. 